\title{
A new attraction-detachment model for explaining flow sliding in clay-rich tephras
}

Kluger, Max O.

Moon, Vicki G.

Kreiter, Stefan

Lowe, David J.

Churchman, G. J.

Hepp, Daniel A.

Seibel, David

Jorat, M. Ehsan

Mörz, Tobias

This is the accepted manuscript (C) 2016 Geological Society of America

The published article is available from:

http://geology.gsapubs.org/content/45/2/131 
Publisher: GSA

Journal: GEOL: Geology

DOI:10.1130/G38560.1

1 A new attraction-detachment model for explaining flow

2 sliding in clay-rich tephras

3 Max O. Kluger ${ }^{1}$, Vicki G. Moon ${ }^{2}$, Stefan Kreiter ${ }^{1}$, David J. Lowe ${ }^{2}$, G.J.

4 Churchman $^{3}$, Daniel A. Hepp ${ }^{1}$, David Seibel ${ }^{1}$, M. Ehsan Jorat ${ }^{4}$, and Tobias Mörz ${ }^{1}$

$5 \quad{ }^{1}$ Marum - Center for Marine Environmental Sciences, University of Bremen, Leobener

6 Straße, 28359 Bremen, Germany

$7 \quad{ }^{2}$ School of Science, University of Waikato, Private Bag 3105, Hamilton 3240, New

$8 \quad$ Zealand

$9{ }^{3}$ School of Agriculture, Food and Wine, University of Adelaide, Adelaide 5005, Australia

$10{ }^{4}$ School of Science, Engineering and Technology, Abertay University, Dundee, DD11HG,

$11 U K$

12 ABSTRACT

13 Altered pyroclastic (tephra) deposits are highly susceptible to landsliding, leading

14 to fatalities and property damage every year. Halloysite, a low-activity clay mineral, is

15 often associated with landslide-prone layers within altered tephra successions, especially

16 in deposits with high sensitivity, which describes the post-failure strength loss. However,

17 the precise role of halloysite in the development of sensitivity, and thus in sudden and

18 unpredictable landsliding, is unknown. Here we show that an abundance of mushroom-

19 cap-shaped (MCS) spheroidal halloysite governs the development of sensitivity, and

20 hence proneness to landsliding, in altered rhyolitic tephras, North Island, New Zealand.

21 We found that a highly sensitive layer, which was involved in a flow slide, has a

22 remarkably high content of aggregated MCS spheroids with substantial openings on one 
Publisher: GSA

Journal: GEOL: Geology

DOI:10.1130/G38560.1

23 side. We suggest that short-range electrostatic and van der Waals' interactions enabled

24 the MCS spheroids to form interconnected aggregates by attraction between the edges of

25 numerous paired silanol and aluminol sheets that are exposed in the openings and the

26 convex silanol faces on the exterior surfaces of adjacent MCS spheroids. If these weak

27 attractions are overcome during slope failure, multiple, weakly-attracted MCS spheroids

28 can be separated from one another and the prevailing repulsion between exterior MCS

29 surfaces results in a low remolded shear strength, a high sensitivity, and a high propensity

30 for flow sliding. The evidence indicates that the attraction-detachment model explains the

31 high sensitivity and contributes to an improved understanding of the mechanisms of flow

32 sliding in sensitive, altered tephras rich in spheroidal halloysite.

\section{INTRODUCTION}

34 Most East Asian and western Pacific countries are located in tectonically active,

35 high-rainfall areas where landslides are a major natural hazard. These landslides are

36 typically triggered by rainstorms or earthquakes, and are responsible for fatalities and

37 enormous property damage every year. Many destructive landslides have occurred in

38 pyroclastic deposits in Japan, Indonesia, Hong Kong, and New Zealand (Chau et al.,

39 2004; Chigira, 2014; Moon, 2016), such deposits often containing layers rich in clay

40 minerals formed mainly by chemical weathering either during pedogenesis or diagenesis.

41 In regions with predominantly rhyolitic volcanism, halloysite is a common clay mineral

42 (Churchman and Lowe, 2012) and is therefore potentially a key geological factor

43 increasing the risk of landslides (Kirk et al., 1997; Chigira, 2014). Halloysite is a 1:1

$44 \mathrm{Si}$ :Al layered aluminosilicate member of the kaolin subgroup that exhibits various 
Publisher: GSA

Journal: GEOL: Geology

DOI:10.1130/G38560.1

45 structural morphologies including tubes, spheroids, polyhedrons, plates and books

46 (Joussein et al., 2005; Cunningham et al., 2016).

47 Spheroidal halloysite, in particular, has been recognized in landslide-prone layers

48 of pyroclastic material in Japan (Tanaka, 1992) and New Zealand (Smalley et al., 1980).

49 Smalley et al. (1980) linked a high content of spheroidal halloysite to high sensitivity.

50 Sensitivity refers to the post-failure strength loss in the failure zone during landsliding,

51 and is quantified in the laboratory as the ratio of the undisturbed to remolded undrained

52 shear strength at the same water content (Terzaghi, 1944). High sensitivities were first

53 described for post-glacial, brackish and marine clayey sediments in the Northern

54 Hemisphere (Skemption and Northey, 1952) that are subject to landslides with

55 dimensions and long runout distances difficult to predict. In this study, we investigate

56 processes that have led to high sensitivity in halloysite-rich pyroclastic materials in order

57 to improve landslide-hazard evaluation.

\section{GEOLOGICAL SETTING}

59 Much of the central part of New Zealand's North Island is covered by thick

60 rhyolitic tephras (Lowe, 2011) derived from eruptions in the Taupo Volcanic Zone

61 (Briggs et al., 2005), which are often altered into halloysite-rich successions. We focus

62 here on a coastal flow slide at Omokoroa, Bay of Plenty (Fig. 1A), where $\sim 10,000 \mathrm{~m}^{3}$ of

63 material were transported downslope over long distance into a lagoon in 1979 (Moon et

64 al., 2015), as well as two minor reactivations in 2011 and 2012. The 1979 event was

65 likely initiated in a white, highly sensitive layer with high spheroidal halloysite

66 concentration (Smalley et al., 1980), lacking any detectable allophane (Cunningham et

67 al., 2016). 
Publisher: GSA

Journal: GEOL: Geology

DOI:10.1130/G38560.1

68 We have analyzed a 40 m-long sediment core, Omok-1, which was bored via

69 rotary flush drilling in unfailed material near the headwall (Fig. 1B). The lithology of

70 Omok-1 was determined by correlation with units of a previously-studied adjacent

71 headwall face (Moon et al., 2015) comprising a succession mainly of Quaternary rhyolitic

72 tephras: overlying lignite at the base of the core, the Pahoia Tephra sequence includes the

73 Te Puna ignimbrite ( 0.93 Ma), and a series of altered tephras, which are informally

74 divided into lower and upper Pahoia Tephra units based on two distinct paleosols (P1 and

75 P3). All these deposits and paleosols are overlain by successions of younger altered

76 tephras called Hamilton Ash beds ( 0.35 to $\sim 0.05 \mathrm{Ma})$ and late Quaternary tephras

77 (< 0.05 Ma) (Fig. 1C and 2A). The lower Pahoia Tephras include the 0.3-m-thick, white,

78 highly sensitive clay-rich layer which failed in 1979 (Fig. 1C), having high porosity and

79 high natural water content (Smalley et al., 1980).

80 METHODS

81 We performed laboratory vane shear tests on samples from the Pahoia Tephra

82 sequence and Hamilton Ash beds to measure the sensitivity $S$ :

$83 \quad S=s_{u} / s_{r}(1)$

84 where the undisturbed strength $\left(s_{u}\right)$ was measured on the intact surface of the split

85 core, and the remolded strength $\left(s_{r}\right)$ was measured on core samples with the same water

86 content, which have been kneaded by hand for $10 \mathrm{~min}$ (Jacquet, 1990). Halloysite

87 concentration in bulk samples was measured by X-ray diffraction (XRD) using a Philips

88 PW analytical defractometer and quantification was performed using QUAX (Vogt et al.,

89 2002). Scanning electron microscopy (SEM) was undertaken with a Zeiss Supra40

90 microscope on 24 shock-frozen, freeze-dried, and gold-coated bulk core samples (Reed, 
Publisher: GSA

Journal: GEOL: Geology

DOI:10.1130/G38560.1

91 2005). The relative abundances of halloysite particles having distinct morphologies were

92 quantified using a point-counting approach (Frolov and Maling, 1969). Six representative

93 SEM-images of planar soil surfaces were chosen for each sample and at least 600

94 particles were counted based on rectangular grids. In the white, highly sensitive layer, the

95 change of halloysite particle arrangement upon remolding was quantified by comparing

9620 SEM images of undisturbed and remolded material, providing > 1000 counts,

97 respectively. The spheroid diameters were measured from six representative particles per

98 SEM image.

99 HIGHLY SENSITIVE SLIDE-PRONE LAYER DOMINATED BY SPHEROIDAL 100 HALLOYSITE

101 The sensitivity is low in the upper Pahoia Tephras, especially in the paleosols P2

102 and P3 (Fig. 2A, B). However, the sensitivity tends to increase with depth, reaching

103 values of 15-20 in the lower Pahoia Tephras. The highest sensitivity (Rosenqvist, 1953)

104 of $S=55$, and the lowest remolded shear strength within the profile of $s_{r}=1.4 \mathrm{kPa}$, were

105 measured in the white, highly sensitive layer at $23 \mathrm{~m}$ depth.

106 The upper Pahoia Tephras have a halloysite content of 10-20 wt.\%, and are

107 comprised almost entirely of tubular halloysite (Fig. 2C, D). The lower Pahoia Tephras

108 have 40-50 wt.\% halloysite comprising mostly spheroidal particles. In the highly

109 sensitive layer, $76 \%$ of the halloysite is spheroidal, and the spheroid sizes are greater than

110 those in the surrounding layers (Fig. 2D). The 3D line plot reveals a clear correlation

111 between high sensitivities and high halloysite bulk concentration, and a high content of

112 spheroids with large diameters (Fig. 2F). The high sensitivity is associated with low

113 remolded shear strength rather than with high undisturbed shear strength (Fig. 2G). 
Publisher: GSA

Journal: GEOL: Geology

DOI:10.1130/G38560.1

114 We found that deposits with high tubular halloysite content hampered sensitivity

115 development, whereas halloysite spheroids facilitate sensitivity and dominate the highly

116 sensitive layer at $23 \mathrm{~m}$ depth within the lower Pahoia Tephras. The highly sensitive layer

117 has low remolded shear strength consequent after failure, which, together with its high

118 water content (Smalley et al., 1980), partly contributed to the long runout distance of the

119 flow slide at Omokoroa.

120 NEW HALLOYSITE MORPHOLOGY

121 We present here first observations of a previously unreported halloysite particle

122 morphology that is visible in the SEM images of the remolded halloysite fabrics of the

123 highly sensitive layer. In the undisturbed state, the spheroidal halloysites are distinctly

124 aggregated into networks of well-connected particles (Fig. 3E, F). After remolding,

125 however, most of the aggregates have broken apart into small, loose clusters or individual

126 halloysite particles that are typically $\sim 250-400 \mathrm{~nm}$ in diameter (Fig. 3G, H). Individual

127 spheroids have distinctive 'deformities' in the form of openings $\sim 80-160 \mathrm{~nm}$ in diameter

128 on one side. These openings were previously hidden by contact with other spheroids. The

129 deformities give the particles an ovate "mushroom-cap" appearance. Point-counting

130 individual mushroom-caps in both undisturbed (aggregated) and remolded

131 (disaggregated) samples showed that the observable mushroom-caps were much more

132 abundant in the remolded samples, increasing from $4.4 \pm 3.2 \%$ to $44.9 \pm 11.6 \%$.

133 ATTRACTION-DETACHMENT MODEL FOR FLOW SLIDING IN ALTERED

\section{TEPHRAS}

135 The open-sided, mushroom-cap-shaped halloysite morphology has not been

136 reported previously. Because this particular morphology overwhelmingly occurs in the 
Publisher: GSA

Journal: GEOL: Geology

DOI:10.1130/G38560.1

137 highly sensitive slide-prone layer, we hypothesize that this unique particle shape controls

138 the mechanical behavior of halloysite clays.

139 Halloysite is composed of an Al-octahedral (aluminol) sheet with a net positive

140 charge and a Si-tetrahedral (silanol) sheet with a net negative charge at $\mathrm{pH}$ values

141 between $\sim 2$ and $\sim 8$ (Fig. 3I) (Churchman et al., 2016). The two sheets have slightly

142 different dimensions, with the silanol sheet being larger. This misfit in the sheet sizes

143 causes the halloysite layer to be curved (Churchman and Lowe, 2012), with the larger

144 negatively-charged silanol sheet on the outside of the curvature and the positively-

145 charged smaller aluminol sheet on the inside. The halloysite spheroids observed in our

146 study are most likely composed of concentrically stacked 1:1 layers, i.e., with an onion-

147 like structure, as shown in numerous studies including those on spheroidal halloysite

148 derived from altered tephras in New Zealand, Japan, and Argentina (Wada et al., 1977;

149 Kirkman, 1981; Cravero et al., 2012; Berthonneau et al., 2015). For a perfect halloysite

150 spheroid, the outermost silanol surface carries a net negative charge and hence the

151 electrostatic interactions between individual spheroids would be repulsive (Fig. 3I). Our

152 study shows, however, a halloysite structure where both silanol and aluminol layers are

153 exposed at spheroid openings and therefore charges within the openings would

154 correspondingly be weakly positive or neutral overall (Fig. 3J), as indicated from charge

155 density-functional tight-binding modeling applied to halloysite nanotubes (Guimarães et

156 al., 2010). If sufficient numbers of positively charged openings are exposed, the

157 electrostatic interactions between them and the negative exterior silanol surfaces would

158 allow the mushroom-cap-shaped spheroids to form stacked aggregates (Fig. 3K). If the

159 paired silanol and aluminol sheets exposed in the openings are neutral overall, then a net 
Publisher: GSA

Journal: GEOL: Geology

DOI:10.1130/G38560.1

160 increase in particle attraction will still occur because electrostatic repulsion is reduced

161 and the larger contact areas lead to higher van der Waals' forces (Israelachvili, 2011).

162 During diagenesis via hydrolysis of volcanic glass (Cunningham et al., 2016), the

163 halloysite spheroids may form consecutively on top of one another in pore spaces,

164 generating the distinct openings during synthesis. The attractive forces between the

165 openings and the convex exterior surfaces are demonstrably strong enough to allow for

166 the formation of aggregates, but also permit easy disaggregation by mechanical

167 detachment during shear (Fig. 3L). New random contacts between convex silanol

168 surfaces probably lead to a decrease in average attraction between particles. We posit that

169 the detachment of attractive spheroidal particle contacts, in the presence of abundant

170 water having negligible interaction with soil-water ions because of the inactive nature of

171 halloysite (Smalley et al., 1980), leads to the very low post-failure shear strength,

172 facilitating a flow slide with long runout distance. The interparticle, attraction-

173 detachment model appears to successfully explain (at nanoscale dimensions) the post-

174 failure behavior of the highly sensitive tephra layer at Omokoroa that is dominated by the

175 imperfect halloysite spheroids. The question therefore arises if similar altered tephras

176 elsewhere have high contents of spheroidal halloysite with potentially hidden mushroom-

177 cap forms, and if such forms helped mobilize other landslides in the past.

\section{CONCLUSIONS}

179 We investigated a sequence of altered, rhyolitic Quaternary tephras in New

180 Zealand, and the reasons why a landslide-prone layer dominated by spheroidal halloysite

181 was highly sensitive. We explain this high sensitivity with an electrostatic attraction-

182 detachment model. Weakly positive or neutral charges on silanol and aluminol sheet 
Publisher: GSA

Journal: GEOL: Geology

DOI:10.1130/G38560.1

183 edges exposed in the concave openings of spheroidal halloysite particles were attracted to

184 the negatively-charged convex silanol surfaces of adjacent spheroids. Such short-range

185 attractions between spheroid openings, and the exterior surfaces of adjacent spheroids,

186 stabilize an aggregated halloysite framework. If the aggregates are detached by

187 remolding, the loose arrangement of the spheroids exhibits low remolded shear strength.

188 We suggest that the attraction-detachment model, based on the identification of

189 mushroom-cap halloysite morphologies, provides a potential key for the identification of

190 sensitive altered tephras that are predisposed to sudden failure that triggers landsliding.

\section{ACKNOWLEDGMENTS}

192 This research was funded by the DFG-Research Center MARUM (Bremen

193 University) through INTERCOAST and University of Waikato. We thank C. Schulze for

194 vane shear tests, B. Steinborn and C. Vogt for XRD analyses, P. Witte, A. Hübner, C.

195 Schott, S. Buchheister, and V. Diekamp for laboratory assistance, M. Ikari, F. Sense, J.

196 Lane, and P. Pasbakhsh for comments, and F. Terrible, J. K. Torrance, F. Cravero, M.

197 McSaveney, and an anonymous expert, for helpful reviews.

198 REFERENCES CITED

199 Berthonneau, J., Grauby, O., Jeannin, C., Chaudanson, D., Joussein, E., and Baronnet, A.,

$200 \quad 2015$, Native morphology of hydrated spheroidal halloysite observed by

201 environmental transmission electron microscopy: Clays and Clay Minerals, v. 63,

202 p. 368-377, doi:10.1346/CCMN.2015.0630503.

203 Briggs, R., Houghton, B., McWilliams, M., and Wilson, C., 2005, 40Ar/39Ar ages of

204 silicic volcanic rocks in the Tauranga-Kaimai area, New Zealand: dating the

205 transition between volcanism in the Coromandel Arc and the Taupo Volcanic Zone: 
Publisher: GSA

Journal: GEOL: Geology

DOI:10.1130/G38560.1

New Zealand Journal of Geology and Geophysics, v. 48, p. 459-469, doi:10.1080/00288306.2005.9515126.

208 Chau, K., Sze, Y., Fung, M., Wong, W., Fong, E., and Chan, L., 2004, Landslide hazard

209 analysis for Hong Kong using landslide inventory and GIS: Computers \&

210 Geosciences, v. 30, p. 429-443, doi:10.1016/j.cageo.2003.08.013.

211 Chigira, M., 2014, Geological and geomorphological features of deep-seated catastrophic

212 landslides in tectonically active regions of Asia and implications for hazard mapping:

213 Episodes, v. 37, p. 284-294.

214 Churchman, G.J., and Lowe, D.J., 2012, Alteration, formation, and occurrence of

215 minerals in soils, in Huang, P. M., Li, Y., and Sumner, M. E., eds., Handbook of Soil

216 Sciences. Properties and Processes, 2nd edition: Boca Raton, Florida, CRC Press, p.

$217 \quad 20.21-20.72$.

218 Churchman, G.J., Pasbakhsh, P., Lowe, D.J., and Theng, B.K.G., 2016, Unique but

219 diverse: some observations on the formation, structure, and morphology of

220 halloysite: Clay Minerals, v. 51, p. 395-416, doi:10.1180/claymin.2016.051.3.16.

221 Cravero, F., Maiza, P., and Marfil, S., 2012, Halloysite in Argentinian deposits: origin

222 and textural constraints: Clay Minerals, v. 47, p. 329-340,

223 doi:10.1180/claymin.2012.047.3.04.

224 Cunningham, M. J., Lowe, D. J., Wyatt, J. B., Moon, V. G., and Jock Churchman, G., 225 2016, Discovery of halloysite books in altered silicic Quaternary tephras, northern

226 New Zealand: Clay Minerals, v. 51, p. 351-372, doi:10.1180/claymin.2016.051.3.16.

227 Frolov, Y., and Maling, D., 1969, The accuracy of area measurement by point counting

228 techniques: The Cartographic Journal, v. 6, p. 21-35, doi:10.1179/caj.1969.6.1.21. 
Publisher: GSA

Journal: GEOL: Geology

DOI:10.1130/G38560.1

229 Guimarães, L., Enyashin, A.N., Seifert, G., and Duarte, H.A., 2010, Structural, electronic,

230 and mechanical properties of single-walled halloysite nanotube models: The Journal

231 of Physical Chemistry C, v. 114, p. 11358-11363, doi:10.1021/jp100902e.

232 Israelachvili, J.N., 2011, Intermolecular and Surface Forces (3rd Edition): Waltham,

233 Massachusetts, Academic Press, 704 p.

234 Jacquet, D., 1990, Sensitivity to remoulding of some volcanic ash soils in New Zealand:

235 Engineering Geology, v. 28, p. 1-25, doi:10.1016/0013-7952(90)90031-U.

236 Joussein, E., Petit, S., Churchman, J., Theng, B., Righi, D., and Delvaux, B., 2005,

237 Halloysite clay minerals - a review: Clay Minerals, v. 40, p. 383-426,

238 doi:10.1180/0009855054040180.

239 Kirk, P., Campbell, S., Fletcher, C., and Merriman, R., 1997, The significance of primary

240 volcanic fabrics and clay distribution in landslides in Hong Kong: Journal of the

241 Geological Society, v. 154, p. 1009-1019, doi:10.1144/gsjgs.154.6.1009.

242 Kirkman, J.H., 1981, Morphology and structure of halloysite in New Zealand tephras:

243 Clays and Clay Minerals, v. 29, p. 1-9, doi:10.1346/CCMN.1981.0290101.

244 Lowe, D.J., 2011, Tephrochronology and its application: a review: Quaternary

245 Geochronology, v. 6, p. 107-153, doi:10.1016/j.quageo.2010.08.003.

246 Moon, V.G., Lowe, D.J., Cunningham, M.J., Wyatt, J.B., de Lange, W.P., Churchman,

247 G.J., Mörz, T., Kreiter, S., Kluger, M.O., and Jorat, M.E., 2015, Sensitive

248 pyroclastic-derived halloysitic soils in northern New Zealand: interplay of

249 microstructure, minerals, and geomechanics, in Rotonda, T. et al., eds.,Volcanic

250 Rocks and Soils. Proceedings of the International Workshop on Volcanic Rocks and

251 Soils, Lacco Ameno, Ischia Island, Italy: London, Taylor and Francis, p. 3-21. 
Publisher: GSA

Journal: GEOL: Geology

DOI:10.1130/G38560.1

252 Moon, V., 2016, Halloysite behaving badly: geomechanics and slope behaviour of

253 halloysite-rich soils: Clay Minerals, v. 51, p. 517-528,

254 doi:10.1180/claymin.2016.051.3.09.

255 Reed, S.J.B., 2005, Electron Microprobe Analysis and Scanning Electron Microscopy in

256 Geology: Cambridge, UK, Cambridge University Press, 212 p,

257 doi:10.1017/CBO9780511610561.

258 Rosenqvist, I.T., 1953, Considerations on the sensitivity of Norwegian quick-clays:

259 Geotechnique, v. 3, p. 195-200, doi:10.1680/geot.1953.3.5.195.

260 Skemption, A., and Northey, R., 1952, The sensitivity of clays: Geotechnique, v. 3,

261 p. 30-53, doi:10.1680/geot.1952.3.1.30.

262 Smalley, I., Ross, C.W., and Whitton, J., 1980, Clays from New Zealand support the

263 inactive particle theory of soil sensitivity: Nature, v. 288, p. 576-577,

264 doi:10.1038/288576a0.

265 Tanaka, K., 1992, Slope hazards and clay minerals: Nendo Kagaku, v. 32, p. 16-22.

266 Terzaghi, K., 1944, Ends and Means in Soil Mechanics: Engineering Journal, v. 27,

267 p. $608-615$.

268 Vogt, C., Lauterjung, J., and Fischer, R.X., 2002, Investigation of the clay fraction $(<2$

$269 \mu \mathrm{m})$ of the Clay Minerals Society Reference Clays: Clays and Clay Minerals, v. 50,

270 p. $388-400$, doi:10.1346/000986002760833765.

271 Wada, S.-I.-, Aoki, K., and Wada, K., 1977, The interior structure of spherical halloysite

272 particles: Clay Science, v. 5, p. 113-121.

273

274 FIGURE CAPTIONS 
Publisher: GSA

Journal: GEOL: Geology

DOI:10.1130/G38560.1

276 Figure 1. A: Map of Tauranga Harbour, New Zealand, with the Taupo Volcanic Zone

277 (TVZ) as main source for Quaternary tephras at the study site. B: 3D-view of the

278 Bramley Drive flow slide at Omokoroa; red line marks the position of the profile in C. C:

279 Profile through the flow slide with simplified stratigraphy and associated paleosols (P1-

280 4) of core Omok-1 and ages (in Ma) after Moon et al. (2015).

282 Figure 2. A: Stratigraphy of core Omok-1 after Moon et al. (2015) showing the main

283 lithological units as defined in Figure 1, three paleosols (P1-3), and the highly sensitive

284 white layer at 23-m depth (hatched area). B: Undisturbed $\left(s_{u}\right)$ and remolded $\left(s_{r}\right)$ shear

285 strength, and sensitivity (S). C: Halloysite bulk concentration. D: Cumulative volume \%

286 (c. \%) of halloysite morphologies with bars indicating average standard deviations. E:

287 Average spheroid sizes with standard deviations depicted by fill patterns. F: 3D line plot

288 illustrating the relationship between spheroid content, sensitivity, spheroid size, and

289 halloysite concentration; gray graded areas enable trends in sensitivity to be visualized.

290 G: Dependency between sensitivity and shear strength.

291

292 Figure 3. SEM-images of spheroids (A), polyhedrons (B), tubes (C), and plates (D)

293 representing the main halloysite morphologies in the Pahoia Tephra sequence. SEM-

294 images from the highly sensitive layer of undisturbed and multiply connected halloysite

295 spheroids (E, F) and remolded spheroids (G, H) showing smaller clusters or detached

296 spheroids within a much looser particle network. 1: Exposed layers in spheroid openings.

297 2: Partially separated halloysite spheroids. 3: Detached mushroom-cap-shaped halloysite 
Publisher: GSA

Journal: GEOL: Geology

DOI:10.1130/G38560.1

298 spheroid. I: Electrostatic field proximal to halloysite nanotubes with colored equipotential

299 surfaces (ES), modified with permission from Guimarães et al. (2010). Copyright 2010

300 American Chemical Society. J: Conceptual mushroom-cap-shaped spheroid cross-section

301 and the weak electrostatic and/or van der Waals' attractions arising between the exposed

302 silanol-aluminol sheets in spheroid openings and the negatively-charged convex exterior

303 surfaces; enlargement is adapted from Berthonneau et al. (2015). Circles with + and -

304 relate to the positive and negative electrostatic field proximal to the spheroid's exterior

305 surface. Mushroom-cap-shaped spheroids connect with one another between concave

306 openings and convex outer spheroid surfaces, forming aggregates (K) which are partly

307 detached because of remolding (L). 


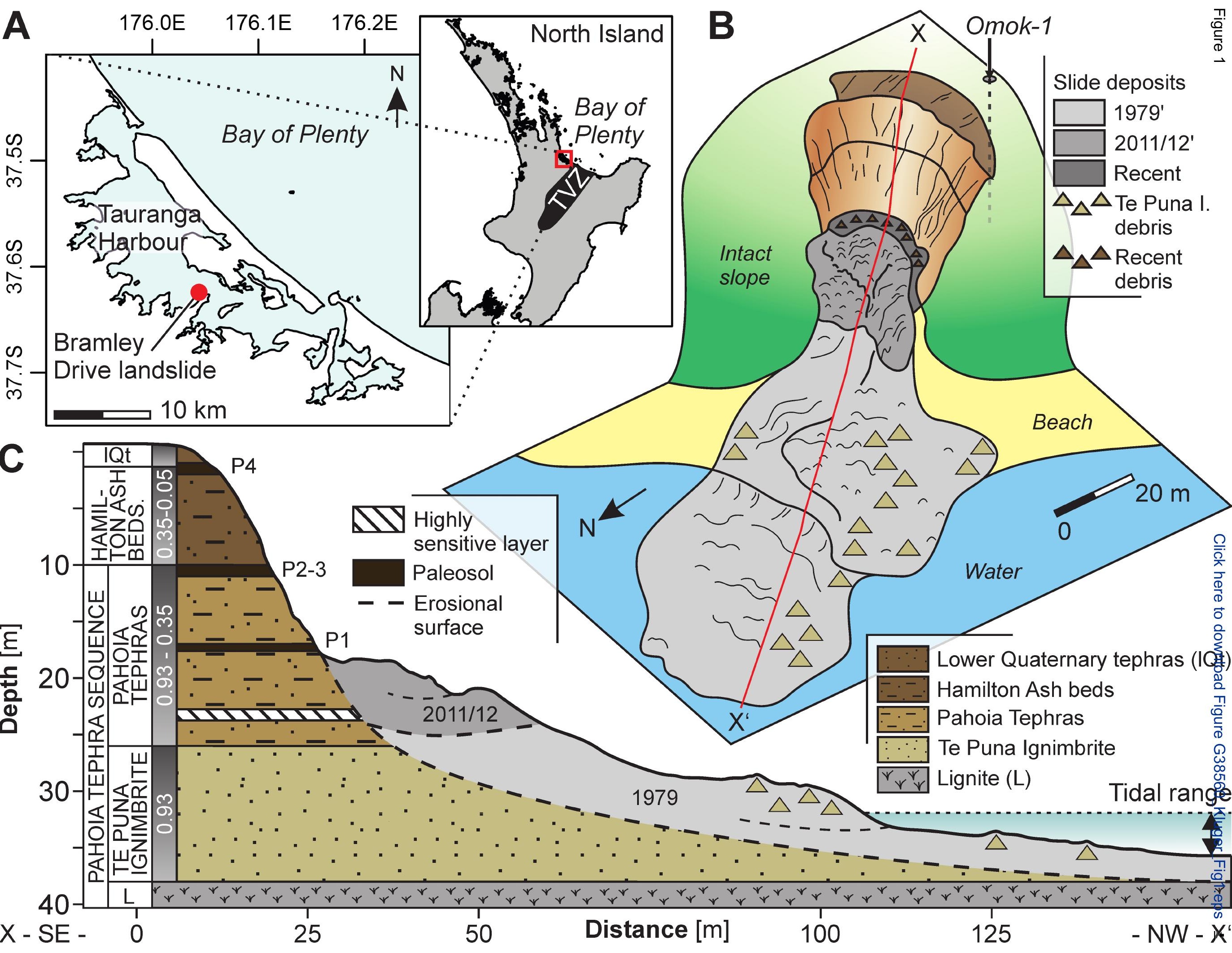



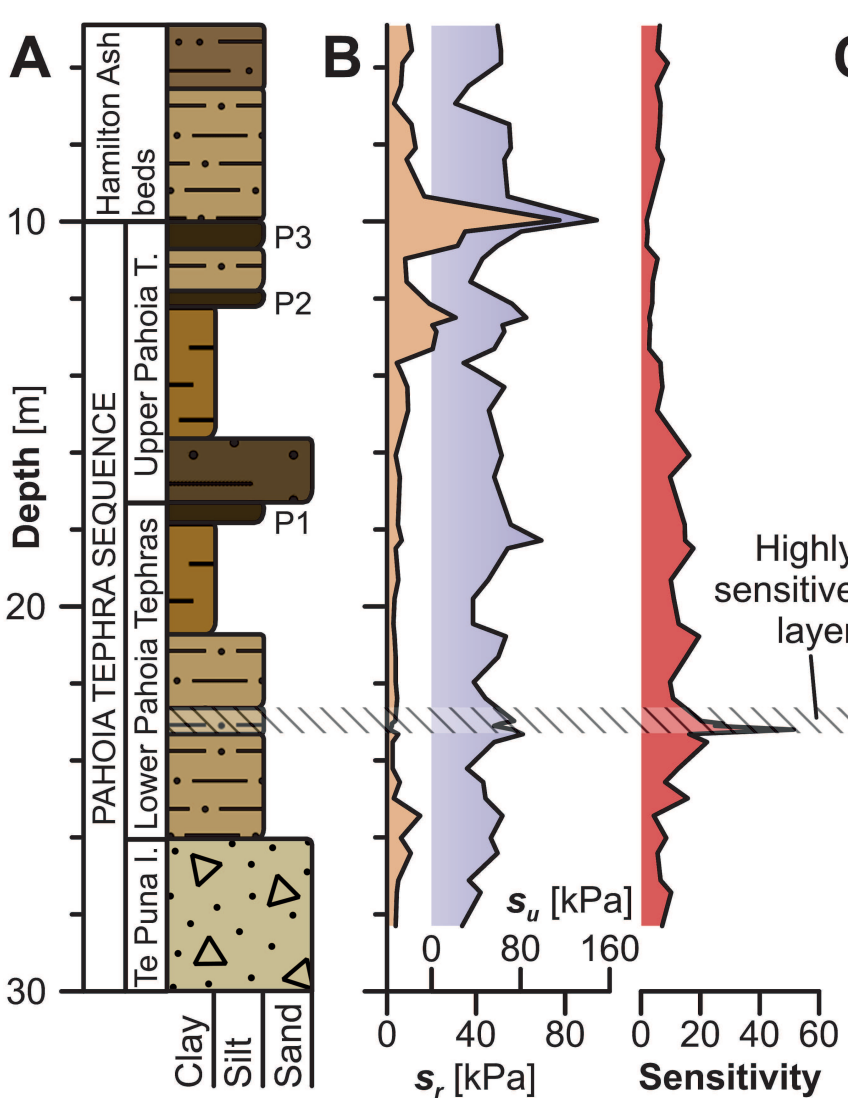

$$
S[-]
$$

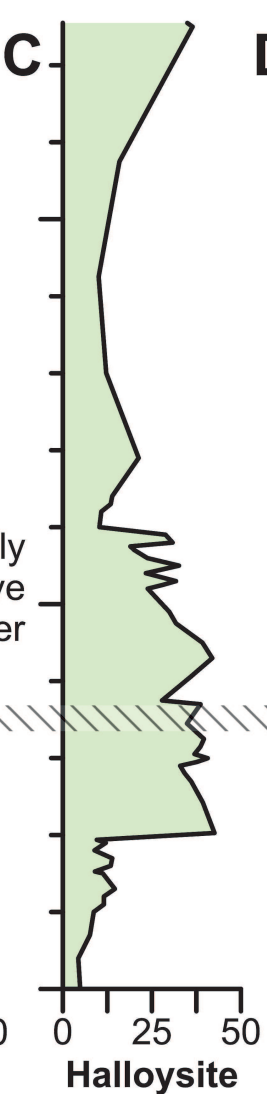

[wt.\%]

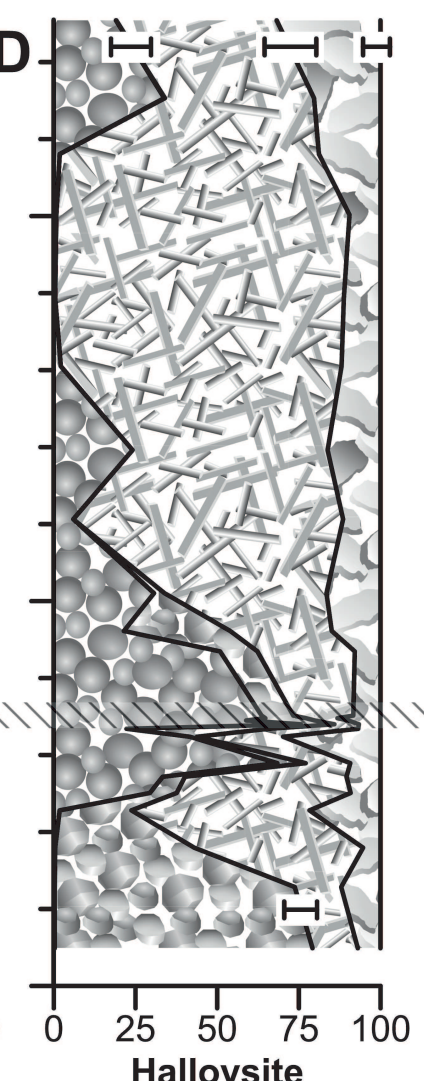
morphology [c. \%]

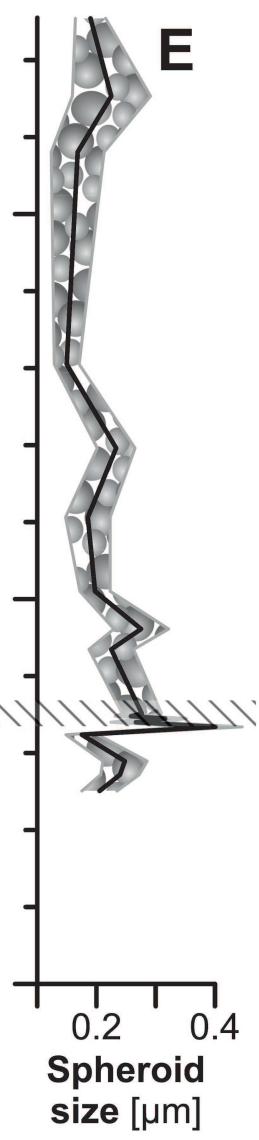

Sandy SILT $\nabla: A$ Pumiceous silty SAND Silty SAND $\square$ Silt PALEOSOL

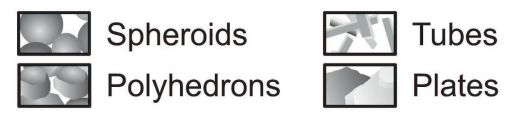

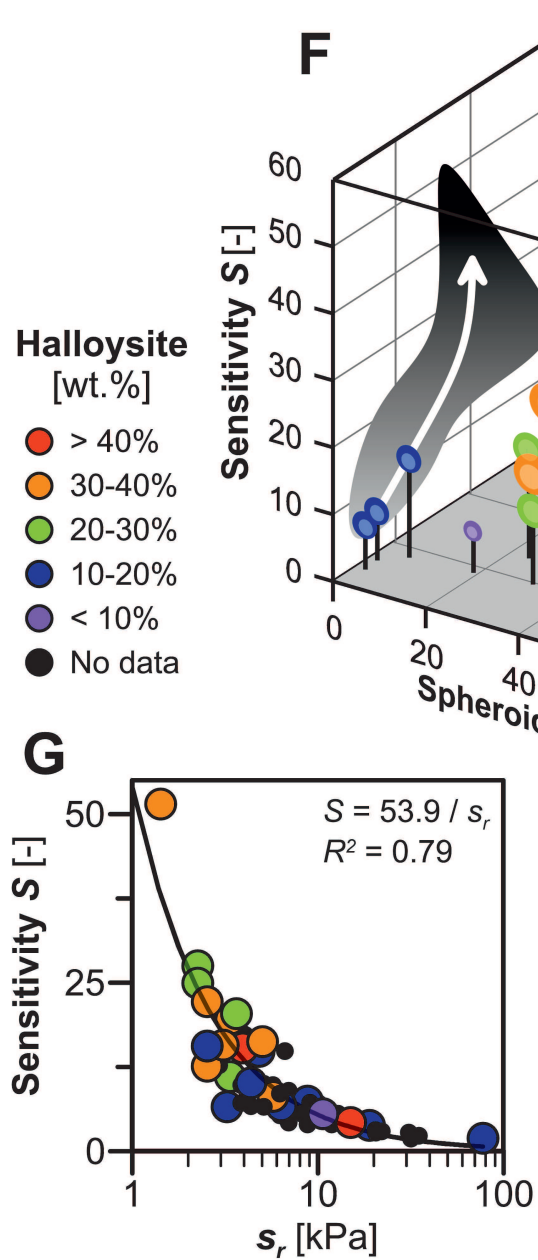

aalloysite [wt.\%]

O $>40 \%$

$30-40 \%$

O $20-30 \%$

$10-20 \%$

O $<10 \%$

No data

G

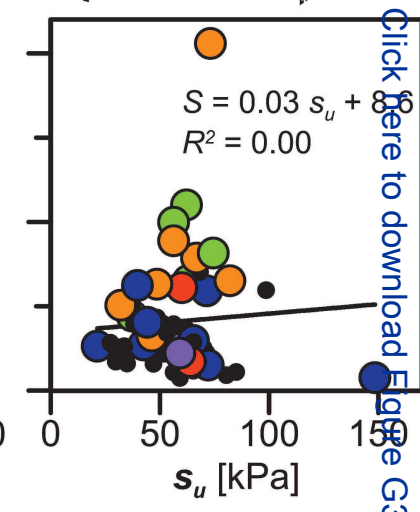



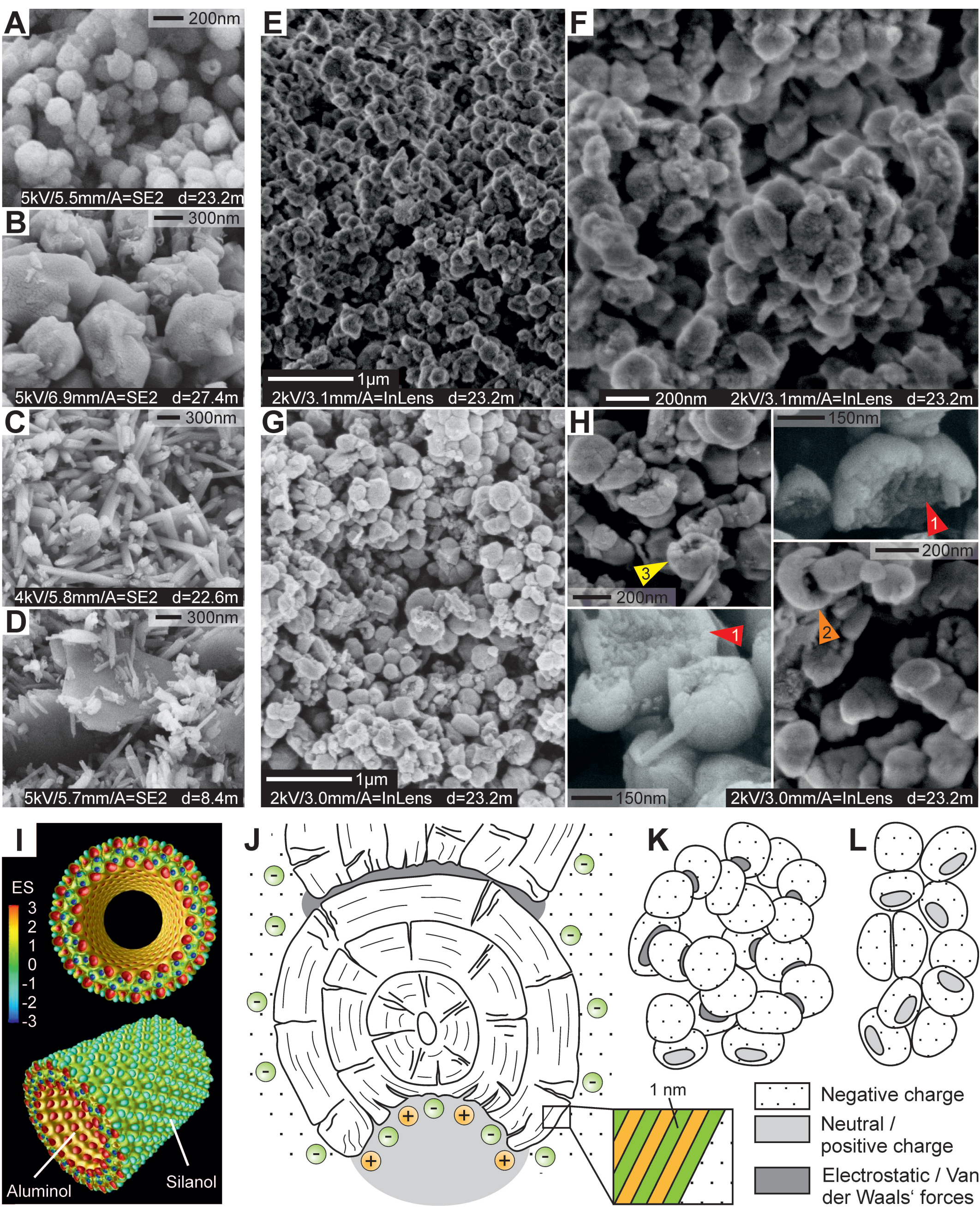